\title{
Linking Gut Microbiota, Metabolic Syndrome and Metabolic Health among a Sample of Obese Egyptian Females
}

\author{
Nayera E. Hassan ${ }^{1}$ D, Sahar A. El-Masry ${ }^{1 *}$ D , Ayat Nageeb ${ }^{1}$, Mohamed S. El Hussieny ${ }^{1}$ D, Aya Khali $\left.\right|^{1}$ (D), Manal Aly ${ }^{1}$ (D) \\ Mohamed Selim², Khadija Alian ${ }^{1}$ D, Enas Abdel Rasheed ${ }^{3}$, Mai Magdy Abdel Wahed ${ }^{3}$ D, Darine Amine ${ }^{1}$ (D) \\ ${ }^{1}$ Department of Biological Anthropology, Medical Research and Clinical Studies Institute, National Research Centre, Giza, \\ Egypt; ${ }^{2}$ Department of Researches and Applications of Complementary Medicine, Medical Research and Clinical Studies \\ Institute, National Research Centre, Giza, Egypt; ${ }^{3}$ Department of Clinical and Chemical Pathology, Medical Research and \\ Clinical Studies Institute, National Research Centre, Giza, Egypt
}

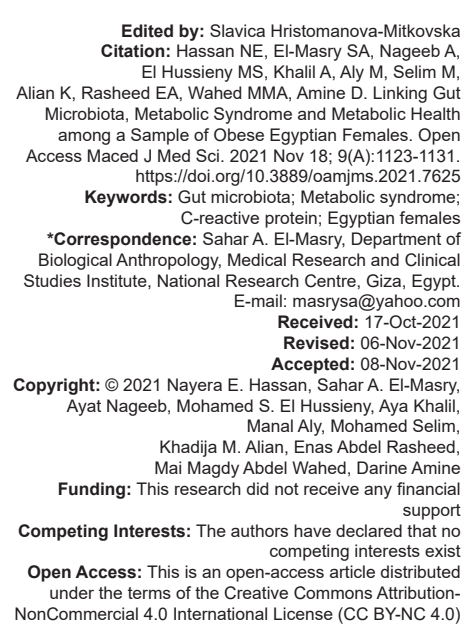

\section{Abstract}

BACKGROUND: Studies of the gut microbiota have revealed a great link to obesity and metabolic syndrome (MetS).

AIM: The aim of this study was to review the dysbiosis of gut microbiota in terms of the components of MetS among a sample of obese Egyptian female patients and to assess current potential gut microbiota targeted therapies for the treatment of MetS

SUBJECTS AND METHODS: This study is a cross-sectional study included 82 obese Egyptian women. All participants were subjected to anthropometric assessment; and laboratory evaluation of fasting blood sugar (FBS), insulin, C-reactive protein (CRP), lipid profile, and insulin resistance homeostasis model assessment (HOMA), in addition to fecal microbiota analysis for Lactobacillus, Bifidobacteria, Firmicutes and Bacteroid.

RESULTS: Among obese group with MetS, Firmicutes/Bacteroidetes (F/B) ratio was negatively associated with HOMA and positively associated with serum cholesterol and low-density lipoprotein (LDL), while Lactobacillus was negatively associated with serum cholesterol. Among obese group without MetS, (F/B) ratio is negatively associated with Waist circumference (central obesity marker) and positively associated with CRP (inflammatory marker), while Lactobacillus was positively correlated with FBS and HOMA, and Bifidobacteria was negatively associated with serum cholesterol and LDL.

CONCLUSION: The two beneficial types the Lactobacillus and Bifidobacteria supplementation in the form of probiotic with therapeutic treatment and decreasing of WC have their important role in controlling and treating hypertension serum cholesterol and LDL levels, among obese females even with MetS.

\section{Introduction}

Metabolic syndrome (MetS) is rapidly growing worldwide health concern with estimation that over one billion people globally [1]. It is a cluster of co-occurring pathological conditions, including insulin resistance (IR), abdominal obesity, hypertension and dyslipidemia [2].

The criteria for diagnosing MetS are designated by values for obesity (e.g. waist circumference [WC] or body mass index [BMI]), triglyceride (TG), high-density lipoprotein cholesterol (HDL-C) and hypertension [3]. Obesity and metabolic disease are complex multifactorial diseases that result from interaction of genetic and environmental factors [4]. Several studies demonstrated that the human gut microbiota, the complex microbial community living inside the human gastrointestinal tract, plays a significant role in the pathogenesis of MetS [5], [6], [7]. They postulated that the composition of microbiota found in the gut of obese individuals showed dissimilar diversity in comparison with that of the microbiota of lean individuals [8], [9].

Alterations in the gut microbiota composition or diversity are known as dysbiosis [10], [11]. Human Gut dysbiosis is linked to many pathologic conditions disturbing the energy metabolism; such as obesity, type 2-diabetes, and atherosclerosis [12]. The microbiota in the human gut is mostly composed of bacterial phyla: Firmicutes and Bacteroidetes (F/B); in addition to Bifidobacteria and Lactobacillus [13]. The association between the two dominant phyla, expressed as the $(F / B)$ ratio, has been associated with several pathological disorders [14].

Dietary choices influence human health through modification of the gastrointestinal microbiota. Regarding the impact of dietary protein on gut microbial composition, a study showed that protein consumption positively correlated with overall microbial diversity, and that consumption of pea and whey protein extract has been found to increase gut Bifidobacterium 
and Lactobacillus [15]. On the contrary, bile-tolerant anaerobes such as Bacteroides were found to increase with animal-based protein consumption [16]. A study of Fava et al. [17], showed that a high-fat diet increased total counts of Bacteroides, while consumption of a low fat diet led to increased fecal abundance of Bifidobacterium with concomitant reductions in fasting glucose and total cholesterol (TC). Carbohydrates ability to modify the gut microbiota was also studied, Eid et al. [18], found that human subjects fed high levels of glucose, fructose, and sucrose in the form of date fruits had increased relative abundance of Bifidobacteria, with reduced Bacteroides. On the other hand, Carvalho-Wells et al. [19], reported that. nondigestible carbohydrates rich in wheat bran and whole grain were linked to the increase in gut Bifidobacteria and Lactobacilli.

Thus, describing the microbiota involved in the dysbiosis is essential as they are emerging as a hopeful target for the nutritional or therapeutic strategies for management of MetS. For example, the overgrowth of potentially pathogenic species could be treated through targeted antimicrobial agents while the disappearance of beneficial microbiota could be treated by the administration of specific probiotics such as Lactobacillus rhamnosus and Bifidobacterium lactis [20].

Hence, the purpose of this research is to review the dysbiosis of gut microbiota in terms of the components of MetS among a sample of obese Egyptian female patients; recognize the relationship between microbiota status and laboratory markers of MetS and to assess current potential gut microbiota targeted therapies for the treatment of MetS among a sample of obese Egyptian females.

\section{Subjects and Methods}

This study was cross-sectional study, included 82 obese Egyptian women. Their ages were ranged between 25 and 60 years with mean age $41.62 \pm 10.70$ years. They were recruited and randomly chosen, from all employees and workers; of all categories; of the "National Research Centre (NRC)," Egypt. A written informed consent was obtained from all participants after being informed about the purpose of the study. This research paper was derived from a cross-sectional survey of a project funded by NRC Egypt, 2019-2022 entitled "Gut Microbiota in Obesity and MetS among obese women: Interactions of the Microbiome, Epigenetic, Nutrition and Probiotic Intervention." (12 ${ }^{\text {th }}$ Research Plan of the NRC), with an approval obtained from Ethics Committee of NRC (Registration Number is 19/236).

\section{Methods}

For each participated woman, blood pressure (BP), anthropometric measurements, laboratory investigations, and microbiota analysis were done.

$B P$

BP was measured using the standardized mercury sphygmomanometer with a suitable cuff size. It was measured on the left arm while the participated women were sitting relaxed for $5 \mathrm{~min}$. Two readings were obtained, and the average was recorded. Systolic BP (SBP); determined by the onset of the "tapping" Korotkoff sounds (K1), while the fifth Korotkoff sound (K5), or the disappearance of Korotkoff sounds, as the definition of diastolic BP (DBP) were recorded.

\section{Anthropometric measurements}

Body weight, height and WC were measured, following the recommendations of the "International Biological Program" [21]. Body weight (Wt) was determined to the nearest $0.01 \mathrm{~kg}$ using a Seca Scale Balance, with the woman wearing minimal clothes and with no shoes. Body height $(\mathrm{Ht})$ was measured to the nearest $0.1 \mathrm{~cm}$ using a Holtain portable anthropometer. WC was measured using non-stretchable plastic tape; approximated to the nearest $0.1 \mathrm{~cm}$. WC was measured atthe midpoint between the lower curvature of the last fixed rib and the superior curvature of the iliac crest, with the woman in an upright standing position and their arms alongside the body, feet together, and abdomen relaxed. BMI was calculated (BMI: weight [in kilograms] divided by height [in meters squared]). The participated women were all chosen as obese; as their BMI $\geq 30 \mathrm{~kg} / \mathrm{m}^{2}$.

\section{Blood sampling and laboratory investigations}

In the morning, venous blood samples (after 12-h fasting) were drawn from the participated women, using venipuncture. Biochemical parameters were performed on fasting sera that were stored at $-70^{\circ} \mathrm{C}$ until used for assessment of fasting blood sugar (FBS), insulin, C-reactive protein (CRP), and lipid profile. All were done in the laboratory of "Mediucal Excellence Research Center MERC" which is a part of "NRC," Egypt.

FBS level was measured using the automated clinical chemistry analyzer Olympus AU 400 analyzer. Serum insulin was assessed using Enzyme Immunoassay Test Kit Catalog No. E29-072 (Immunospec Corporation). Then IR was calculated according to Matthews et al. [22] using the following equation: $I R=$ fasting glucose $(\mathrm{mg} / \mathrm{dl}) \times$ fasting insulin $(\mu \mathrm{lU} / \mathrm{ml}) / 405$. 
The assay of the serum CRP was performed by Enzyme Linked Immunosorbent Assay (ELISA) kits, Cat No.: RAP002 [23], (https://www.mybiosource.com.)

Estimation of lipid profile: Serum levels of TC, TG, and HDL-C were measured by standardized enzymatic procedures; using kits supplied by Roche Diagnostics (Mannheim, Germany) on the Olympus AU 400 automated clinical chemistry analyzer. Lowdensity lipoprotein cholesterol (LDL-C) was calculated according to formula of Friedewald et al. [24] as follows: LDL-C = TC-TG/5 + HDL-C (This formula is valid when TG must be $<400 \mathrm{mg} / \mathrm{dl}$ ).

Clinically, a patient is considered to have MetS when three or more of the following five conditions exist, which are (i) $W C \geq 88 \mathrm{~cm}$ in women, (ii) $\mathrm{BP}$ $\geq 135 / 85 \mathrm{mmHg}$, (iii) TG $\geq 150 \mathrm{mg} / \mathrm{dl}$, (iv) HDL-C $<50 \mathrm{mg} /$ $\mathrm{dl}$ in women, and (v) fasting glucose $\geq 100 \mathrm{mg} / \mathrm{dl}$ [25].

\section{Microbiota analysis}

The proportion of Lactobacillus and Bifidobacteria; and (F/B) ratio strains were assessed in the stool of all participants using the real time polymerase chain reaction (PCR). Specimen collection and preparation: Stool was collected by defecation in a plain sterilized container allowed to be frozen. Specimen Storage and Preparation: stool was frozen on at $-20^{\circ} \mathrm{C}$. The primers and probes were used to detect Bifidobacterium spp. and Lactobacillus spp; and Firmicutes spp. and Bacteroidetes spp., where based on 16S rRNA gene sequences retrieved from the National Center for Biotechnology Information databases by means of the Entrez program [26].

Reagents provided by kits: DNA extraction Kit. Assay procedure: DNA extraction: The QIAamp DNA Stool Minikit (Qiagen) was used to extract DNA from one gram of fresh or frozen stool sample according to the manufacturer's instructions. Bacterial quantification by real-time PCR was done.

\section{Statistical analysis}

Data were analyzed using the Statistical Package for Social Sciences (SPSS) (SPSS/Windows Version 18, SPSS Inc., Chicago, IL, USA). Normality of data was tested using the Kolmogorov-Smirnov test. The data were normally distributed. Hence, the parametric tests were used. All participated women were obese; with $\mathrm{BMI}>30 \mathrm{~kg} / \mathrm{m}^{2}$. They were classified according to the presence of MetS criteria into two subgroups: 59 obese without MetS (have no or <2 criteria of MetS), and 23 obese with MetS (have 3 or more criteria of MetS).

The parametric data were expressed as mean $\pm S D$, The various parametric variables of the two groups were analyzed and compared using independent t-test. Pearsońs correlation test was used to assess the relations between each enterotypes of microbiota and patient's clinical and metabolic parameters among the two groups. $p<0.05$ was regarded as statistically significant for all tests.

\section{Results}

Table 1 showed means \pm SD and the range of the BP, characteristic anthropometric parameters, and laboratory and microbiota investigations of the obese women with and without multiple sclerosis (MS). The obese women with MetS were significantly older, and had highly significant higher values of BP (both systolic and diastolic), BMI, WC, homeostasis model assessment (HOMA) and TG, and significant higher value of serum insulin; than those without MetS.

Table 1: Mean $\pm S D$ and range of the Characteristic anthropometric parameters and BP of the obese non Met $S$ women and Met $S$ patients $(n=82)$

\begin{tabular}{|c|c|c|c|}
\hline \multirow[t]{2}{*}{ Parameters } & Without Met S (n: 59) & With Met S (n: 23) & $p$ \\
\hline & \multicolumn{3}{|l|}{ Mean \pm SEM and range } \\
\hline Age (year) & $\begin{array}{l}43.61 \pm 9.89 \\
(25-60)\end{array}$ & $\begin{array}{l}48.52 \pm 9.95 \\
(29-60)\end{array}$ & $0.037^{*}$ \\
\hline \multicolumn{4}{|l|}{$\mathrm{BP}(\mathrm{mm} \mathrm{Hg})$} \\
\hline Systolic & $\begin{array}{l}115.38 \pm 10.38 \\
(90.0-150.0)\end{array}$ & $\begin{array}{l}137.50 \pm 22.35 \\
(100.0-190.0)\end{array}$ & $0.000^{* \star}$ \\
\hline Diastolic & $\begin{array}{l}72.92 \pm 6.95 \\
(60.0-90.0)\end{array}$ & $\begin{array}{l}84.32 \pm 14.50 \\
(60.0-110.0)\end{array}$ & $0.000^{* *}$ \\
\hline \multicolumn{4}{|l|}{ Anthropometry } \\
\hline Weight (kg) & $\begin{array}{l}91.82 \pm 16.29 \\
(54.0-134.10)\end{array}$ & $\begin{array}{l}100.10 \pm 20.40 \\
(73.8-136.20)\end{array}$ & 0.058 \\
\hline Height $(\mathrm{cm})$ & $\begin{array}{l}159.12 \pm 5.85 \\
(146.0-171.0)\end{array}$ & $\begin{array}{c}157.59 \pm 7.28 \\
(146.0-172.0)\end{array}$ & 0.324 \\
\hline BMI $\left(\mathrm{kg} / \mathrm{m}^{2}\right)$ & $\begin{array}{l}36.19 \pm 5.64 \\
(24.99-49.42)\end{array}$ & $\begin{array}{l}40.01 \pm 5.89 \\
(29.41-51.43)\end{array}$ & $0.008^{\star *}$ \\
\hline WC $(\mathrm{cm})$ & $\begin{array}{l}102.66 \pm 15.42 \\
(70.0-133.0)\end{array}$ & $\begin{array}{l}113.96 \pm 12.85 \\
(93.138 .0)\end{array}$ & $0.003^{* *}$ \\
\hline \multicolumn{4}{|c|}{ (1) } \\
\hline FBS (mg/dl) & $\begin{array}{l}112.77 \pm 42.57 \\
(70.0-191.0)\end{array}$ & $\begin{array}{l}130.13 \pm 46.37 \\
(90.0-285.0)\end{array}$ & 0.116 \\
\hline Serum Insulin $(\mu \mathrm{lU} / \mathrm{ml})$ & $\begin{array}{l}12.22 \pm 6.76 \\
(1.6-28.00)\end{array}$ & $\begin{array}{l}16.73 \pm 7.40 \\
(2.0-31.5)\end{array}$ & $0.011^{*}$ \\
\hline HOMA & $\begin{array}{l}3.47+2.19 \\
(0.21-9.48)\end{array}$ & $\begin{array}{l}5.27+2.46 \\
(0.56-9.67)\end{array}$ & $0.002^{* *}$ \\
\hline CRP $(\mathrm{ng} / \mathrm{ml})$ & $\begin{array}{l}7243.15+2981.27 \\
(1900-12000)\end{array}$ & $\begin{array}{l}6933.48+1795.72 \\
(4200-8900)\end{array}$ & 0.655 \\
\hline \multicolumn{4}{|l|}{ Lipid profile } \\
\hline Cholesterol (mg/dl) & $\begin{array}{l}195.57 \pm 5.80 \\
(99.0-277.0)\end{array}$ & $\begin{array}{l}208.52 \pm 36.86 \\
(134.0-281.0)\end{array}$ & 0.169 \\
\hline $\mathrm{HDL}(\mathrm{mg} / \mathrm{dl})$ & $\begin{array}{l}57.00 \pm 11.52 \\
(39.0-74.0)\end{array}$ & $\begin{array}{l}54.35 \pm 10.23 \\
(40.0-75.0)\end{array}$ & 0.344 \\
\hline $\mathrm{LDL}(\mathrm{mg} / \mathrm{dl})$ & $\begin{array}{l}117.55 \pm 33.45 \\
(68.00-188.0)\end{array}$ & $\begin{array}{l}128.25 \pm 5.04 \\
(73.0-190.0)\end{array}$ & 0.477 \\
\hline TG $(\mathrm{mg} / \mathrm{dl})$ & $\begin{array}{l}98.51 \pm 34.33 \\
(50.00-172.0)\end{array}$ & $\begin{array}{l}154.39 \pm 79.17 \\
(69.0-254.0)\end{array}$ & $0.000^{* *}$ \\
\hline \multicolumn{4}{|l|}{ Microbiota } \\
\hline Log Lactobacillus & $\begin{array}{l}6.11 \pm 0.13 \\
(4.67-7.91)\end{array}$ & $\begin{array}{l}5.85 \pm 0.15 \\
(4.61-7.83)\end{array}$ & 0.167 \\
\hline Log bifido & $\begin{array}{l}6.14 \pm 0.11 \\
(4.61-7.79)\end{array}$ & $\begin{array}{l}6.12 \pm 0.11 \\
(4.85-7.74))\end{array}$ & 0.926 \\
\hline Log Bacteroid & $\begin{array}{l}13.24 \pm 1.51 \\
(10.57-16.68)\end{array}$ & $\begin{array}{l}13.05 \pm 0.26 \\
(10.67-14.68)\end{array}$ & 0.576 \\
\hline Log Firmicutes & $\begin{array}{l}9.45 \pm 1.49 \\
(4.52-11.88)\end{array}$ & $\begin{array}{l}8.91 \pm 1.43 \\
(6.79-11.69)\end{array}$ & 0.141 \\
\hline Log Firmicutes/Bacteroid ratio & $\begin{array}{l}0.73 \pm 0.13 \\
(0.43-1.10)\end{array}$ & $\begin{array}{l}0.69 \pm 0.14 \\
(0.46-1.07)\end{array}$ & 0.350 \\
\hline
\end{tabular}

BMI: Body mass index, BMR: Basal metabolic rate, WC: Waist circumference, SBP: Systolic blood HDL-C: High density lipoprotein-cholesterol, LDL-C: Low density lipoprotein cholesterol, SGPT: Alanine aminotransferase, SGOT: Aspartate aminotransferase, Met S. Metabolic Syndrome, $p<0.05$. Significan aminotransferase, SGOT: Aspartate aminotransferase, Met S: Metabo
difference, $p<0.01$ : Highly significant difference, BP: Blood pressure.

Reviewing Table 1, it was also, found that Bacteroidetes bacteria were the most prevalent type 
Table 2: Pearson's correlations between each enterotypes of microbiota and patient's clinical and metabolic parameters among obese females without MetS

\begin{tabular}{|c|c|c|c|c|c|c|c|c|c|c|}
\hline \multirow[t]{2}{*}{ Variables } & \multicolumn{2}{|c|}{ Log Lactobacillus } & \multicolumn{2}{|c|}{ Log bifido } & \multicolumn{2}{|c|}{ Log Bacteroid } & \multicolumn{2}{|c|}{ Log Firmicutes } & \multicolumn{2}{|c|}{ Log Firmicutes/Bacteroid ratio } \\
\hline & $\mathrm{r}$ & $\mathrm{p}$ & $r$ & $\mathrm{p}$ & $r$ & $\mathrm{p}$ & $r$ & $\mathrm{p}$ & $\mathrm{r}$ & $\mathrm{p}$ \\
\hline \multicolumn{10}{|l|}{$\mathrm{BP}(\mathrm{mm} \mathrm{Hg})$} & 0.075 \\
\hline SBP & 0.016 & 0.908 & -0.113 & 0.423 & -0.085 & 0.549 & -0.199 & 0.157 & -0.151 & 0.284 \\
\hline DBP & -0.107 & 0.452 & -0.124 & 0.383 & -0.252 & 0.072 & -0.236 & 0.092 & -0.079 & 0.579 \\
\hline \multicolumn{11}{|l|}{ Anthropometry } \\
\hline Weight (kg) & 0.171 & 0.196 & -0.036 & 0.788 & 0.089 & 0.505 & 0.043 & 0.748 & -0.018 & 0.895 \\
\hline Height $(\mathrm{cm})$ & -0.139 & 0.294 & -0.066 & 0.619 & -0.147 & 0.267 & -0.120 & 0.367 & -0.029 & 0.827 \\
\hline BMI $\left(\mathrm{kg} / \mathrm{m}^{2}\right)$ & 0.256 & 0.051 & -0.073 & 0.584 & 0.165 & 0.210 & 0.111 & 0.402 & 0.002 & 0.990 \\
\hline WC $(\mathrm{cm})$ & 0.040 & 0.763 & 0.230 & 0.080 & 0.106 & 0.423 & -0.214 & 0.103 & -0.272 & $0.037^{\star}$ \\
\hline \multicolumn{11}{|l|}{ Lab } \\
\hline FBS (mg/dl) & 0.296 & $0.031^{*}$ & 0.059 & 0.676 & 0.312 & $0.023^{*}$ & 0.030 & 0.832 & -0.170 & 0.223 \\
\hline Serum Insulin $(\mu \mathrm{IU} / \mathrm{ml})$ & 0.176 & 0.208 & -0.088 & 0.529 & 0.207 & 0.136 & 0.147 & 0.293 & -0.019 & 0.892 \\
\hline HOMA & 0.301 & $0.029^{*}$ & -0.012 & 0.930 & 0.342 & $0.012^{*}$ & 0.197 & 0.158 & -0.064 & 0.648 \\
\hline $\mathrm{CRP}(\mathrm{ng} / \mathrm{ml})$ & -0.108 & 0.443 & -0.101 & 0.471 & -0.194 & 0.163 & 0.210 & 0.131 & 0.273 & $0.048^{*}$ \\
\hline \multicolumn{11}{|l|}{ Lipid profile } \\
\hline Cholesterol (mg/dl) & 0.242 & 0.080 & -0.295 & $0.032^{*}$ & 0.040 & 0.774 & -0.072 & 0.608 & -0.071 & 0.614 \\
\hline $\mathrm{HDL}(\mathrm{mg} / \mathrm{dl})$ & 0.256 & 0.065 & -0.074 & 0.600 & 0.197 & 0.156 & -0.156 & 0.265 & -0.233 & 0.093 \\
\hline LDL (mg/dl) & 0.236 & 0.089 & -0.320 & $0.019^{*}$ & -0.004 & 0.980 & -0.076 & 0.589 & -0.048 & 0.734 \\
\hline $\mathrm{TG}(\mathrm{mg} / \mathrm{dl})$ & -0.061 & 0.665 & -0.009 & 0.947 & 0.043 & 0.762 & 0.063 & 0.653 & 0.007 & 0.963 \\
\hline \multicolumn{11}{|l|}{ Microbiota } \\
\hline Log Lactobacillus & & & 0.087 & 0.512 & 0.645 & $0.000^{\star \star}$ & 0.131 & 0.321 & -0.281 & $0.031^{*}$ \\
\hline Log bifido & 0.087 & 0.512 & & & 0.547 & $0.000^{* *}$ & 0.079 & 0.554 & -0.261 & $0.046^{*}$ \\
\hline Log Bacteroid & 0.645 & $0.000^{* *}$ & 0.547 & $0.000^{* *}$ & & & 0.220 & 0.094 & -0.415 & $0.001^{* *}$ \\
\hline Log Firmicutes & 0.131 & 0.321 & 0.079 & 0.554 & 0.220 & 0.094 & & & 0.788 & $0.000^{\star *}$ \\
\hline Log Firmicutes/Bacteroid ratio & -0.281 & $0.031^{*}$ & -0.261 & $0.046^{*}$ & -0.415 & $0.001^{* *}$ & 0.788 & $0.000^{* *}$ & & \\
\hline
\end{tabular}

p < 0.05 . Significant difference, $p<0.01$ : Highly significant difference, WC: Waist circumference, SBP: Systolic blood pressure, DBP: Diastolic blood pressure, TC: Total cholesterol, TG: Triglyceride, HDL-C: High density

ipoprotein-cholesterol, LDL-C: Low density lipoprotein cholesterol, Met S: Metabolic syndrome, FBS: Fasting blood sugar.

among the studied microbiota, and followed by the gut microbes Firmicutes, followed by the two beneficial types the Lactobacillus and Bifidobacteria. The insignificant decrease in bacteroid was less than the insignificant decrease in Firmicutes, this lead to insignificant minor decrease in F/B ratio.

Pearson 's correlations between each enterotypes of microbiota and patient's clinical and metabolic parameters among obese women in the two groups are presented in Tables 2 and 3. Lactobacillus had significant positive correlations with Bacteroidetes bacteria, and significant negative correlations with (F/B) Ratio among both obese with and without MS groups. Among obese without MS group, Lactobacillus had significant positive correlations with FBS and HOMA. While among obese with MS group,
Lactobacillus had significant negative correlations with serum cholesterol.

Bifidobacteria had significant positive correlations with Bacteroidetes bacteria among both groups. Among obese without MS group, Bifidobacteria had significant negative correlation with serum cholesterol, LDL and (F/B) Ratio.

Bacteroidetes bacteria had significant positive correlations with Lactobacillus and Bifidobacteria, and significant negative correlations with (F/B) ratio among the two groups. Among obese without MS group, Bacteroidetes bacteria had significant positive correlations with age, FBS and HOMA. Among obese with MS group, Bacteroidetes bacteria had significant positive correlations with weight and significant negative correlations with serum cholesterol.

Table 3: Pearson's correlations between each enterotypes of microbiota and patient's clinical and metabolic parameters among obese females with MetS

\begin{tabular}{|c|c|c|c|c|c|c|c|c|c|c|}
\hline \multirow[t]{2}{*}{ Variables } & \multicolumn{2}{|c|}{ Log Lactobacillus } & \multicolumn{2}{|c|}{ Log bifido } & \multicolumn{2}{|c|}{ Log Bacteroid } & \multicolumn{2}{|c|}{ Log Firmicutes } & \multicolumn{2}{|c|}{ Log Firmicutes/Bacteroid ratio } \\
\hline & $r$ & $\mathrm{p}$ & $r$ & $\mathrm{p}$ & $r$ & $\mathrm{p}$ & $r$ & $\mathrm{p}$ & $r$ & $\mathrm{p}$ \\
\hline Age (years) & 0.035 & 0.872 & -0.059 & 0.790 & 0.006 & 0.977 & 0.111 & 0.614 & 0.082 & 0.710 \\
\hline SBP & 0.337 & 0.125 & 0.422 & \multicolumn{7}{|c|}{$\mathrm{BP}(\mathrm{mm} \mathrm{Hg})$} \\
\hline DBP & 0.286 & 0.196 & 0.048 & 0.832 & 0.125 & 0.578 & 0.084 & 0.712 & -0.103 & 0.647 \\
\hline \multicolumn{11}{|l|}{ Anthropometry } \\
\hline Weight (kg) & 0.271 & 0.212 & 0.044 & 0.844 & 0.414 & $0.050^{*}$ & -0.101 & 0.648 & -0.251 & 0.248 \\
\hline Height (cm) & 0.157 & 0.475 & 0.124 & 0.574 & 0.372 & 0.080 & -0.055 & 0.805 & -0.203 & 0.352 \\
\hline BMI $\left(\mathrm{kg} / \mathrm{m}^{2}\right)$ & 0.265 & 0.222 & -0.003 & 0.991 & 0.344 & 0.108 & -0.114 & 0.604 & -0.231 & 0.299 \\
\hline$W C(\mathrm{~cm})$ & 0.180 & 0.412 & -0.027 & 0.904 & 0.330 & 0.125 & 0.010 & 0.965 & -0.145 & 0.510 \\
\hline \multicolumn{11}{|l|}{ Lab } \\
\hline FBS (mg/dl) & -0.114 & 0.606 & -0.054 & 0.807 & -0.068 & 0.758 & -0.147 & 0.502 & -0.097 & 0.658 \\
\hline Serum Insulin $(\mu l U / m l)$ & -0.092 & 0.677 & 0.412 & 0.051 & 0.224 & 0.305 & -0.385 & 0.070 & -0.374 & 0.079 \\
\hline HOMA & -0.153 & 0.485 & 0.294 & 0.174 & 0.134 & 0.543 & -0.441 & $0.035^{\star}$ & -0.392 & 0.064 \\
\hline CRP (ng/ml) & 0.218 & 0.318 & 0.004 & 0.987 & 0.191 & 0.384 & -0.323 & 0.132 & -0.301 & 0.163 \\
\hline \multicolumn{11}{|l|}{ Lipid profile } \\
\hline Cholesterol (mg/dl) & -0.443 & $0.034^{*}$ & -0.260 & 0.231 & -0.451 & $0.031^{\star}$ & 0.454 & $0.029^{*}$ & 0.562 & $0.005^{\star \star}$ \\
\hline $\mathrm{HDL}(\mathrm{mg} / \mathrm{dl})$ & -0.048 & 0.827 & -0.020 & 0.928 & -0.095 & 0.666 & 0.181 & 0.409 & 0.222 & 0.308 \\
\hline LDL (mg/dl) & -0.391 & 0.065 & -0.229 & 0.295 & -0.403 & 0.056 & 0.368 & 0.084 & 0.485 & $0.019^{*}$ \\
\hline $\mathrm{TG}(\mathrm{mg} / \mathrm{dl})$ & -0.296 & 0.170 & -0.184 & 0.402 & -0.265 & 0.222 & 0.288 & 0.183 & 0.300 & 0.164 \\
\hline \multicolumn{11}{|l|}{ Microbiota } \\
\hline Log Lactobacillus & & & 0.166 & 0.449 & 0.659 & $0.001^{\star \star}$ & -0.248 & 0.253 & -0.468 & $0.024^{*}$ \\
\hline Log bifido & 0.166 & 0.449 & & & 0.526 & $0.010^{*}$ & -0.138 & 0.530 & -0.300 & 0.156 \\
\hline Log Bacteroid & 0.659 & $0.001^{\star \star}$ & 0.526 & $0.010^{*}$ & & & -0.261 & 0.230 & -0.631 & $0.001^{\star \star}$ \\
\hline Log Firmicutes & -0.248 & 0.253 & -0.138 & 0.530 & -0.261 & 0.230 & & & 0.907 & $0.000^{\star \star}$ \\
\hline Log Firmicutes/Bacteroid ratio & -0.468 & $0.024^{*}$ & -0.300 & 0.156 & -0.631 & $0.001^{\star \star}$ & 0.907 & $0.000^{\star \star}$ & & \\
\hline
\end{tabular}

(1) Th: Total cholesterol TG: Triglyceride, HDL-C: High density lipoprotein-cholesterol, LDL-C: Low density lipoprotein cholesterol, Met S: Metabolic syndrome, BMI: Body mass index. 
Firmicutes had significant positive correlations with $(F / B)$ ratio among the two groups. Among obese with MS group, Firmicutes had significant positive correlation with serum cholesterol and significant negative correlations with HOMA.

(F/B) Ratio had significant positive correlation with Firmicutes and significant negative correlations with Lactobacillus and Bacteroidetes among the two groups. It had significant negative correlations with Bifidobacteria among obese without MS group. Among obese without MS group, (F/B) ratio had significant positive correlation with $\mathrm{CRP}$, and significant negative correlation with WC. Among obese with MS group, $(\mathrm{F} / \mathrm{B})$ ratio had significant positive correlations with serum cholesterol and LDL, and significant negative correlations with HOMA.

\section{Discussion}

For years, a great deal of research was undertaken for better understanding of the factors leading to MetS. Several studies discussed the significant role played by the human gut microbiota; the complex microbial community living inside the human gastrointestinal tract, in the pathogenesis of MetS [6]. The interaction between gut microbiota and host metabolism was found to either threaten or protect the host from metabolic diseases [27].

Some studies showed that this alterations in the gut microbiota composition; intestinal dysbiosis; causes low-grade inflammation, obesity and consequently MetS [28], while others revealed that dysbiosis could be the result of low-grade inflammation during obesity and MetS [29].

The present study aimed to characterize the gut microbiota of obese women with and without MetS and identify relationship between their microbiota status and metabolic parameters among a sample of obese Egyptian females. Present results revealed that, in spite of the insignificant differences between the 2 studied groups concerning microbiota; obese women without MetS had insignificant higher values of all types of the studied microbiota than those with MetS. While Firmicutes/Bacteroid ratio became insignificant lower among obese with MetS than among those without MetS. This means that development of MetS led to decrease the amount of microbiota and particularly decrease the Firmicutes/Bacteroid ratio; which may be one of the causes of MetS. The insignificant differences in statistical analysis of the microbiota might be related to the use of the log values.

Among obese females with and without MS, F/B ratio had significant negative correlation with Lactobacillus. Confirming our results, the genera
Lactobacillus Probiotics were found to have the potential to reduce the $F / B$ ratio and obesity as the administration of Lactobacillus decreased the F/B ratio in obese mice and reduced fatty acid synthesis, in the liver [30]. In another study, Lactobacillus consumed with a high-fat diet prevented weight gain and decreased the F/B ratio [31].

In the current study, ageing has been suggested to cause changes in the intestinal microbial community. Age had significant positive correlation with Bacteroidetes only among obese females without MS and insignificant in obese females with MS. Similar to current results, the identified microbiome pattern of healthy ageing is characterized by depletion of Bacteroides, while retaining a high Bacteroides dominance into older age due to dysbiosis of obesity, predicts decreased survival in a 4-year follow-up [32].

In the present study, BP had insignificant correlations with Lactobacillus, Firmicutes and F/B ratio among the 2 obese groups. In contrast, some studies have suggested an association between intestinal dysbiosis and hypertension. For example, treating mice with Lactobacillus prevented salt sensitive hypertension [33]. In another experimental study by Adnan et al. [34], gavage feeding the normotensive rats with microbiota from hypertensive rats, led to increases in the F/B ratio and systolic BP.

Concerning the anthropometry, among obese females with MetS, body weight had significant positive correlations with Bacteroidetes. Similarly, Schwiertz et al. [35]; in Germany; studied the fecal microbiota of lean and obese volunteers of both sexes and noted that the proportions of Bacteroides were greater in overweight volunteers than lean ones. On the other side, Crovesy et al. [36] revealed that Bacteroidetes have been associated with normal body weight but the Firmicutes with obesity. The possible cause may be due to dysbiosis in MetS or could be diet-induced effect. In fact, Bacteroidetes encode a greater number of carbohydrate-degrading enzymes than Firmicutes [37].

In the current study, WC had significant negative correlation with F/B Ratio among obese females without MS; confirming dysbiosis. However, Davis, 2016 revealed that the increase in Firmicutes can be associated with augmented uptake of fatty acids, storage of TG in adipocytes and increased hepatic lipogenesis [38]. On the other hand, Bifidobacterium could have the ability to help Bacteroides degrade polysaccharides and inhibit exogenous cholesterol absorption from the small intestine [39], therefore the decrease in Bifidobacterium will increase body adiposity and WC [40].

There was a significant negative correlation between HOMA only with Firmicutes and F/B ratio among obese group with MS. While among obese group without MS, FBS, and HOMA had significant positive correlations with Lactobacillus (which may be 
a protective effect against the development of MS) and Bacteroidetes.

Gut microbiota may affect our body's response to insulin, for this reason, many researchers are interested in targeting the gut microbiota to improve obesity-associated IR and hyperglycemia [41]. Glycemic improvement by probiotics supplements in pre-diabetic individuals has been supported by an Iranian study [42]. Serum CRP is a marker of systemic inflammation, which is elevated in the presence of chronic conditions including obesity, type 2 diabetes, and several components of the MetS [43].

In current study, CRP had significant positive correlations with F/B Ratio among obese group without MetS. Studies had revealed that inflammation in MetS may be triggered by intestinal dysbiosis and involves many chronic multisystem conditions including obesity, atherosclerosis, type 2 diabetes mellitus, and inflammatory bowel disease [44]. In current study, among obese group with MS serum cholesterol and LDL had significant positive correlations with F/B ratio which may be due to a protective increase in Firmicutes to lower hypercholesterolemia and decrease high LDL associated with MS. Furthermore, both serum cholesterol and LDL had significant negative correlation with Bifidobacteria only among obese group without MS, while serum cholesterol only showed significant negative correlation with Lactobacillus and Bacteroides among obese group with MS.

Similarly, meta-analysis studies showed reduction in the level of TC and LDL cholesterol after the use of probiotics, including Lactobacillus and Bifidobacterium [45], [46]. A study in Brazil also showed potential effects of Bifidobacterium in reducing obesity, blood lipids, and some inflammatory markers, which may reduce cardiovascular risk in obese patients [47]. A meta-analysis established that consumption of Lactobacillus has beneficial effects on serum TC and LDL-C levels, while no noticeable changes in serum HDL-C and TG levels [48].

Firmicutes participate in the metabolic process of phenolic compounds, which act as ant diabetic and anti-obesity agents [49]. Thus, this bacterial phylum could have a potential role in the maintenance of normal blood lipids. A study identified that higher abundances of Firmicutes and lower abundances of Bacteroidetes were associated with an optimal therapeutic effect of the lipid lowering agent Rosuvastatin [50].

\section{Conclusion}

Among obese women, gut microbiota had insignificant correlation with either BP or anthropometry, except WC which was negatively associated with F/B
Ratio among obese group without MS. Among obese group with MS, F/B Ratio is negatively associated with HOMA and positively associated with serum cholesterol and LDL, while Lactobacillus and Bacteroidetes are negatively associated with serum cholesterol.

Among obese group without MS, F/B Ratio is negatively associated with WC (obesity marker) and positively associated with CRP (inflammatory marker), while Lactobacillus and Bacteroidetes are positively associated with FBS and HOMA, and Bifidobacteria is negatively associated with serum cholesterol and LDL.

Current findings indicate that gut microbiota may play a crucial role in dyslipidemia. As well, gut micro flora can be implicated in the regulation of lipid, glucose, and energy metabolism.

\section{Limitation of this Study}

The fund of the research was limited, so we did not be able to increase the sample number of obese women regarding laboratory and microbiota analysis. COVID-19 pandemic also was one of the most difficult challenges we met which was a barrier for collection of the study sample.

\section{Acknowledgments}

We would like to acknowledge our institute "NRC;" Egypt"; without their support this study could not be done. Authors are also grateful to everybody participated in this study; the employers of our institute who were the participants of this study, the technicians who helped in the laboratory analysis and the doctors who participated in collection of the data'. Without their help, this study couldn't have been completed.

\section{Author Contribution}

Nayera E. Hassan conceived and designed the study; she is the PI of the project from which this data was derived. Sahar A. El-Masry; statistical analysis and interpretation of the data, she is the Co-PI of the project from which these data were derived. Enas Abdel Rasheed and Mai Magdy Abdel Wahed; responsible about the laboratory investigations. Ayat N. Kamal and Mohamed S. El Hussieny; wrote the draft of the article, Aya Khalil and Manal Mouhamed Aly; supervision on collection of data and references. Mohamed Selim, 
Khadija M Alian and Darine Amin; collected the data. All authors contributed to the collection of references, drafting of the article and final approval of the version to be submitted. All the authors have accepted responsibility for the entire content of this submitted manuscript and approved submission.

\section{References}

1. Saklayen MG. The global epidemic of the metabolic syndrome. Curr Hypertens Rep. 2018;20(2):12. https://doi.org/10.1007/ s11906-018-0812-z

PMid:29480368

2. Srikanthan K, Feyh A, Visweshwar H, Shapiro JI, Sodhi K Systematic review of metabolic syndrome biomarkers: A panel for early detection, management, and risk stratification in the west Virginian population. Int J Med Sci. 2016;13(1):25-38 https://doi.org/10.7150/ijms. 13800

PMid:26816492

3. Ford ES. The metabolic syndrome and mortality from cardiovascular disease and all-causes: Findings from the national health and nutrition examination survey II mortality study. Atherosclerosis. 2004;173(2):309-14. https://doi. org/10.1016/j.atherosclerosis.2003.12.022

PMid:15064107

4. Kim MH, Yun KE, Kim J, Park E, Chang Y, Ryu S, et al. Gut microbiota and metabolic health among overweight and obese individuals. Sci Rep. 2020;10(1):19417. https://doi.org/10.1038/ s41598-020-76474-8

PMid:33173145

5. Kootte RS, Levin E, Salojärvi J, Smits LP, Hartstra AV Udayappan SD, et al. Improvement of insulin sensitivity after lean donor feces in metabolic syndrome is driven by baseline intestinal microbiota composition. Cell Metab. 2017;26(4):611-9. https://doi.org/10.1016/j.cmet.2017.09.008 PMid:28978426

6. He Y, Wu W, Wu S, Zheng HM, Li P, Sheng HF, et al. Linking gut microbiota, metabolic syndrome and economic status based on a population-level analysis. Microbiome. 2018;6(1):172. https:// doi.org/10.1186/s40168-018-0557-6.

PMid:30249275

7. Wutthi-In M, Cheevadhanarak S, Yasom S, Kerdphoo S, Thiennimitr P, Phrommintikul A, et al. Gut microbiota profiles of treated metabolic syndrome patients and their relationship with metabolic health. Sci Rep. 2020;10(1):10085. https://doi org/10.1038/s41598-020-67078-3

PMid:32572149

8. Moreira AP, Teixeira TF, Gouveia Peluzio MC, de Cássia Gonçalves Alfenas R. Gut microbiota and the development of obesity. Nutr Hosp. 2012;27(5):1408-14. https://doi.org/10.3305/ nh.2012.27.5.5887 PMid:23478685

9. Muscogiuri G, Cantone E, Cassarano S, Tuccinardi D, Barrea L, Savastano S, et al. Gut microbiota: A new path to treat obesity. Int J Obes Suppl. 2019;9(1):10-9. https://doi.org/10.1038/ s41367-019-0011-7 PMid:31391921

10. Henao-Mejia J, Elinav E, Jin C, Hao L, Mehal WZ, Strowig T, et al. Inflammasomemediateddysbiosis regulates progression of NAFLD and obesity. Nature. 2012;482(7384):179-85. https:// doi.org/10.1038/nature10809

PMid:22297845

11. Lim MY, You HJ, Yoon HS, Kwon B, Lee JY, Lee S, et al. The effect of heritability and host genetics on the gut microbiota and metabolic syndrome. Gut. 2017;66(6):1031-8. https://doi. org/10.1136/gutjnl-2015-311326

PMid:27053630

12. Yong, VB. The role of the microbiome in human health and disease: An introduction for clinicians. BMJ. 2017;356:j831. https://doi.org/10.1136/bmj.j831

PMid:28298355

13. Rinninella E, Raoul $P$, Cintoni $M$, Franceschi $F$, Miggiano GA Gasbarrini A, Mele MC. What is the healthy gut microbiota composition? A changing ecosystem across age, environment diet, and diseases. Microorganisms. 2019;7(1):14. https://doi. org/10.3390/microorganisms 7010014 PMid:30634578

14. Magne F, Gotteland M, Gauthier L, Zazueta A, Pesoa S, Navarrete P, Balamurugan R. The firmicutes/bacteroidetes ratio: A relevant marker of gut dysbiosis in obese patients? Nutrients. 2020;12(5):1474. https://doi.org/10.3390/nu12051474 PMid:32438689

15. Świątecka D, Narbad A, Ridgway KP, Kostyra H. The study on the impact of glycated pea proteins on human intestinal bacteria.Int J Food Microbiol. 2011;145(1):267-72. https://doi. org/10.1016/j.ijfoodmicro.2011.01.002

PMid:21276631

16. David LA, Maurice CF, Carmody RN, Gootenberg DB, Button JE, Wolfe $\mathrm{BE}$, et al. Diet rapidly and reproducibly alters the human gut microbiome. Nature. 2014;505(7484):559-63. https://doi. org/10.1038/nature12820

PMid:24336217

17. Fava F, Gitau R, Griffin BA, Gibson GR, Tuohy KM, Lovegrove JA The type and quantity of dietary fat and carbohydrate alter faecalmicrobiome and short-chain fatty acid excretion in a metabolic syndrome "at-risk" population. Int J Obes (Lond). 2013;37(2):216-23. https://doi.org/10.1038/ijo.2012.33 PMid:22410962

18. Eid N, Enani S, Walton G, Corona G, Costabile A, Gibson G et al. The impact of date palm fruits and their component polyphenols, on gut microbial ecology, bacterial metabolites and colon cancer cell proliferation. J Nutr Sci. 2014;3:e46. https:// doi.org/10.1017/jns.2014.16

PMid:26101614

19. Carvalho-Wells AL, Helmolz K, Nodet C, Molzer C, Leonard C McKevith $\mathrm{B}$, et al. Determination of the in vivo prebiotic potential of a maize-based whole grain breakfast cereal: A human feeding study. Br J Nutr. 2010;104(9):1353-6. https://doi.org/10.1017/ S0007114510002084

PMid:20487589

20. Mantegazza C, Molinari P, D'Auria E, Sonnino M, Morelli L, Zuccotti GV. Probiotics and antibiotic-associated diarrhea in children. A review and new evidence on Lactobacillus rhamnosus GG during and after antibiotic treatment. Pharmacol Res. 2018;128:63-72. https://doi.org/10.1016/j.phrs.2017.08.001 PMid:28827186

21. Hiernaux J, Tanner JM. Growth and physical studies. In Weiner JS, Lourie SA, editors. A Guide to Field Methods. Oxford, UK: IBP, Blackwell Scientific Publications; 1969. p. 624

22. Matthews DR, Hosker JP, Rudenski AS, Naylor BA, Treacher DF Turner RC. Homeostasis model assessment: Insulin resistance and beta-cell function from fasting plasma glucose and insulin concentrations in man. Diabetologia. 1985;28(7):412-9. https:// doi.org/10.1007/BF00280883

PMid:3899825 
23. Mitra B, Panja M. High sensitive C-reactive protein: A novel biochemical markers and its role in coronary artery disease. J Assoc Physicians India. 2005;53:25-32. PMid:15857009

24. Friedewald WT, Levy RI, Fredrickson DS. Estimation of the concentration of low-density lipoprotein cholesterol in plasma, without use of the preparative ultracentrifuge. Clin Chem. 1972;18(6):499-502.

PMid:4337382

25. Alberti KG, Eckel RH, Grundy SM, Zimmet PZ, Cleeman JI, Donato $\mathrm{KA}$, et al. Harmonizing the metabolic syndrome: $A$ joint interim statement of the international diabetes federation task force on epidemiology and prevention; national heart, lung, and blood institute; American heart association; world heart federation; international atherosclerosis society; and international association for the study of obesity. Circulation. 2009;120(16):1640-5. https://doi.org/10.1161/ CIRCULATIONAHA.109.192644

PMid:19805654

26. Wheeler HE, Shah KP, Brenner J, Garcia T, Aquino-Michaels K, GTEx Consortium, et al. Survey of the heritability and sparse architecture of gene expression traits across human tissues. PLoS Genet. 2016;12(11):e1006423. https://doi.org/10.1371/ journal.pgen.1006423

PMid:27835642

27. Stephens RW, Arhire L, Covasa M. Gut microbiota: From microorganisms to metabolic organ influencing obesity. Obesity (Silver Spring). 2018;26(5):801-9. https://doi.org/10.1002/ oby. 22179 PMid:29687647

28. Wang $P X$, Deng $X R$, Zhang $\mathrm{CH}$, Yuan HJ. Gut microbiota and metabolic syndrome. Chin Med J (Engl). 2020;133(7):808-16. https://doi.org/10.1097/CM9.0000000000000696 PMid:32106124

29. Yu R, Kim CS, Kang JH. Inflammatory components of adipose tissue as target for treatment of metabolic syndrome. Forum Nutr. 2009;61:95-103. https://doi.org/10.1159/000212742 PMid:19367114

30. Ji YS, Kim HN, Park HJ, Lee JE, Yeo SY, Yang JS, et al. Modulation of the murine microbiome with a concomitant antiobesity effect by Lactobacillus rhamnosus GG and Lactobacillus sakei NR28. Benef Microbes. 2012;3(1):13-22. https://doi. org/10.3920/BM2011.0046 PMid:22348905

31. Ji Y, Park S, Park H, Hwang E, Shin H, Pot B, Holzapfel WH. Modulation of active gut microbiota by Lactobacillus rhamnosus GG in a diet induced obesity murine model. Front Microbiol. 2018;9:710. https://doi.org/10.3389/fmicb.2018.00710 PMid:29692770

32. Wilmanski T, Diener C, Rappaport N, Patwardhan S, Wiedrick J, Lapidus J, et al. Gut microbiome pattern reflects healthy ageing and predicts survival in humans. Nat Metab. 2021;3(2):274-86. https://doi.org/10.1038/s42255-021-00348-0 PMid:33619379

33. Wilck N, Matus MG, Kearney SM, Olesen SW, Forslund K, Bartolomaeus $\mathrm{H}$, et al. Salt-responsive gut commensal modulates T H 17 axis and disease. Nature. 2017;551(7682):585-9. https:// doi.org/10.1038/nature24628 PMid:29143823

34. Adnan S, Nelson JW, Ajami NJ, Venna VR, Petrosino JF, Bryan RM, et al. Alterations in the gut microbiota can elicit hypertension in rats. Physiol Genomics. 2016;49(2):96-104. https://doi.org/10.1152/physiolgenomics.00081.2016 PMid:28011881

35. Schwiertz A, Taras D, Schäfer K, Beijer S, Bos NA, Donus C, et al.
Microbiota and SCFA in lean and overweight healthy subjects. Obesity (Silver Spring). 2010;18(1):190-5. https://doi.org/10.1038/ oby. 2009.167

PMid:19498350

36. Crovesy L, Masterson D, Rosado EL. Profile of the gut microbiota of adults with obesity: A systematic review. Eur J Clin Nutr. 2020;74(9):1251-62. https://doi.org/10.1038/ s41430-020-0607-6

PMid:32231226

37. Mahowald MA, Rey FE, Seedorf H, Turnbaugh PJ, Fulton RS, Wollam A, et al. Characterizing a model human gut microbiota composed of members of its two dominant bacterial phyla. Proc Natl Acad Sci USA. 2009;106(14):5859-64. https://doi. org/10.1073/pnas.0901529106

PMid:19321416

38. Davis CD. The gut microbiome and its role in obesity. Nutr Today. 2016;51(4):167-74. https://doi.org/10.1097/ NT.0000000000000167

\section{PMid:27795585}

39. Sonnenburg JL, Chen CT, Gordon JI. Genomic and metabolic studies of the impact of probiotics on a model gut symbiont and host. PLoS Biol. 2006;4(12):e413. https://doi.org/10.1371/ journal.pbio.0040413

PMid:17132046

40. Yin YN, Yu QF, Fu N, Liu XW, Lu FG. Effects of four Bifidobacteria on obesity in high-fat diet induced rats. World $\mathrm{J}$ Gastroenterol. 2010;16(27):3394-401. https://doi.org/10.3748/ wjg.v16.i27.3394

PMid:20632441

41. Kassaian N, Aminorroaya A, Feizi A, Jafari P, Amini M. The effects of probiotic and synbiotic supplementation on metabolic syndrome indices in adults at risk of Type 2 diabetes: Study protocol for a randomized controlled trial. Trials. 2017;18(1):148. https://doi.org/10.1186/s13063-017-1885-8

PMid:28356129

42. Kassaian N, Feizi A, Aminorroaya A, Jafari P, Ebrahimi MT, Amini M. The effects of probiotics and synbiotic supplementation on glucose and insulin metabolism in adults with prediabetes: A double-blind randomized clinical trial. Acta Diabetol. 2018;55(10):1019-28. https://doi.org/10.1007/ s00592-018-1175-2

PMid:29931423

43. Sproston NR, Ashworth JJ. Role of C-reactive protein at sites of inflammation and infection. Front Immunol. 2018;9:754. https:// doi.org/10.3389/fimmu.2018.00754 PMid:29706967

44. Al Bander Z, Nitert MD, Mousa A, Naderpoor N. The Gut microbiota and inflammation: An overview. Int J Environ Res Public Health. 2020;17(20):7618. https://doi.org/10.3390/ ijerph17207618

PMid:33086688

45. Guo Z, Liu XM, Zhang QX, Shen Z, Tian FW, Zhang $\mathrm{H}$, et al. Influence of consumption of probiotics on the plasma lipid profile A meta-analysis of randomised controlled trials. Nutr Metab Cardiovasc Dis. 2011;21(11):844-50. https://doi.org/10.1016/j. numecd.2011.04.008 PMid:21930366

46. Cho YA, Kim J. Effect of probiotics on blood lipid concentrations: A meta-analysis of randomized controlled trials. Medicine (Baltimore). 2015;94(43):e1714. https://doi.org/10.1097/ MD.0000000000001714

PMid:26512560

47. Bernini LJ, Simão AN, Alfieri DF, Lozovoy MA, Mari NL, de Souza $\mathrm{CH}$, et al. Beneficial effects of Bifidobacterium lactis on lipid profile and cytokines in patients with metabolic syndrome: 
A randomized trial. Effects of probiotics on metabolic syndrome. Nutrition. 2016;32(6):716-9. https://doi.org/10.1016/j. nut.2015.11.001

PMid:27126957

48. Wu Y, Zhang Q, Ren Y, Ruan Z. Effect of probiotic Lactobacillus on lipid profile: A systematic review and meta-analysis of randomized, controlled trials. PLoS One. 2017;12(6):e0178868. https://doi.org/10.1371/journal.pone.0178868 PMid:28594860

49. Eid HM, Wright ML, Anil Kumar NV, Qawasmeh A, Hassan ST,
Mocan $\mathrm{A}$, et al. Significance of microbiota in obesity and metabolic diseases and the modulatory potential by medicinal plant and food ingredients. Front Pharmacol. 2017;8:387. https://doi.org/10.3389/fphar.2017.00387

PMid:28713266

50. Liu $\mathrm{Y}$, Song $\mathrm{X}$, Zhou H, Zhou X, Xia $\mathrm{Y}$, Dong $\mathrm{X}$, et al. Gut microbiome associates with lipid-lowering effect of Rosuvastatin in vivo. Front Microbiol. 2018;9:530. https://doi.org/10.3389/ fmicb.2018.00530

PMid:29623075 